\title{
InSAR monitoring of subsidence induced by underground mining operations
}

\author{
G Falorni TRE ALTAMIRA Inc., Canada \\ S Del Conte TRE ALTAMIRA Inc., Canada \\ F Bellotti TRE ALTAMIRA s.r.l, Italy \\ D Colombo TRE ALTAMIRA s.r.l, Italy
}

\begin{abstract}
Underground cave and longwall mining can produce subsidence of the ground surface. Mapping of the extent and magnitude of ground movement is usually one of the main challenges faced by mine operators and is important for mine planning, operational hazard assessment and to evaluate environmental and socio-economic impacts. Until now, subsidence prediction was based on complex numerical modelling that typically used a small set of discrete data points as input to calibrate the model. These measurements were both spatially and temporally sparse. The advent of interferometric synthetic aperture radar (InSAR) significantly changed this scenario by providing a high density of measurement points with a high sampling frequency in time. Additional beneficial features of InSAR for mine sites include: (i) the provision of information without the need to install ground instrumentation (no need to access remote or hazardous sites), (ii) the capability to perform historical ground deformation analyses thanks to the existence of data archives going back to the 1990s (worldwide coverage is available from at least May 2016), and (iii) millimetric sensitivity to vertical deformation, which allows accurate characterisation of the areas affected by subsidence.
\end{abstract}

Two case studies of InSAR monitoring applied to underground mining operations are presented, highlighting the advantages of combining different InSAR techniques to monitor both slow and fast movements.

Keywords: InSAR, monitoring, underground mining, block/panel caving, slope stability

\section{Introduction}

Ground subsidence is an important hazard that often accompanies underground mining activities. Underground operations such as longwall mining, and block and sublevel caving can produce strong subsidence at the surface, which, in extreme cases, can cause production stoppages, safety risks and damage to infrastructure. The monitoring of surface deformation is, therefore, fundamental for mitigating the risks related to subsidence. The instrumentation used for surface deformation monitoring in and around mining operations is generally based on conventional survey techniques (total stations, levelling, GPS receivers), extensometers and ground-based interferometric synthetic aperture radar (InSAR), but none of these usually offer the high-density, bird's eye view of the movement areas provided by satellite InSAR. In recent years, the complementary use of space-based InSAR with traditional systems has proved to be strategic for operational monitoring and risk assessment.

Beneficial features of InSAR surface monitoring for mine sites include:

- The provision of information without the need to install ground instrumentation (no need to access remote or hazardous sites).

- The wide coverage and high density of information, not achievable with in situ instrumentation.

- The capability to detect both slow and fast movement (from millimetres to metres) by integrating different InSAR techniques. 
The existence of data archives going back to the 1990s initially led to the extensive use of InSAR data to perform historical ground deformation analyses. Successful applications to underground and open pit mines are presented by Carnec and Delacourt (2000), Raucoules et al. (2003), Colesanti et al. (2005), Jung et al. (2007), Herrera et al. (2007), Herrera et al. (2010), Espinosa et al. (2014), lannacone et al. (2014), Paradella et al. (2015) and Sánchez et al. (2017). Recent advances in the satellite space segment and processing algorithms have significantly reduced computational time and the advent of newer satellites with increased spatial resolution and acquisition frequency have increased information density. Near-real-time InSAR monitoring is now widely applied in different mining settings to highlight possible incipient movements in areas not visible to in situ instrumentation.

\section{InSAR overview}

Synthetic aperture radar (SAR) satellites acquire images of the Earth's surface by emitting electromagnetic waves and analysing the reflected signal. InSAR, also referred to as SAR interferometry, consists of the phase comparison of SAR images, acquired at different times with similar looking angles from space or airborne platforms (Gabriel et al. 1989; Massonnet \& Feigl 1998; Rosen et al. 2000; Bamler \& Hartl 1998). The phase difference between two SAR images is proportional to the target motion occurring along the sensor-target line-of-sight (LOS) direction (Figure 1) during that time interval. As SAR satellites are continuously circumnavigating the globe, a number of SAR images can be collected for the same area over time and information about the deformation of the Earth's surface can be extracted.
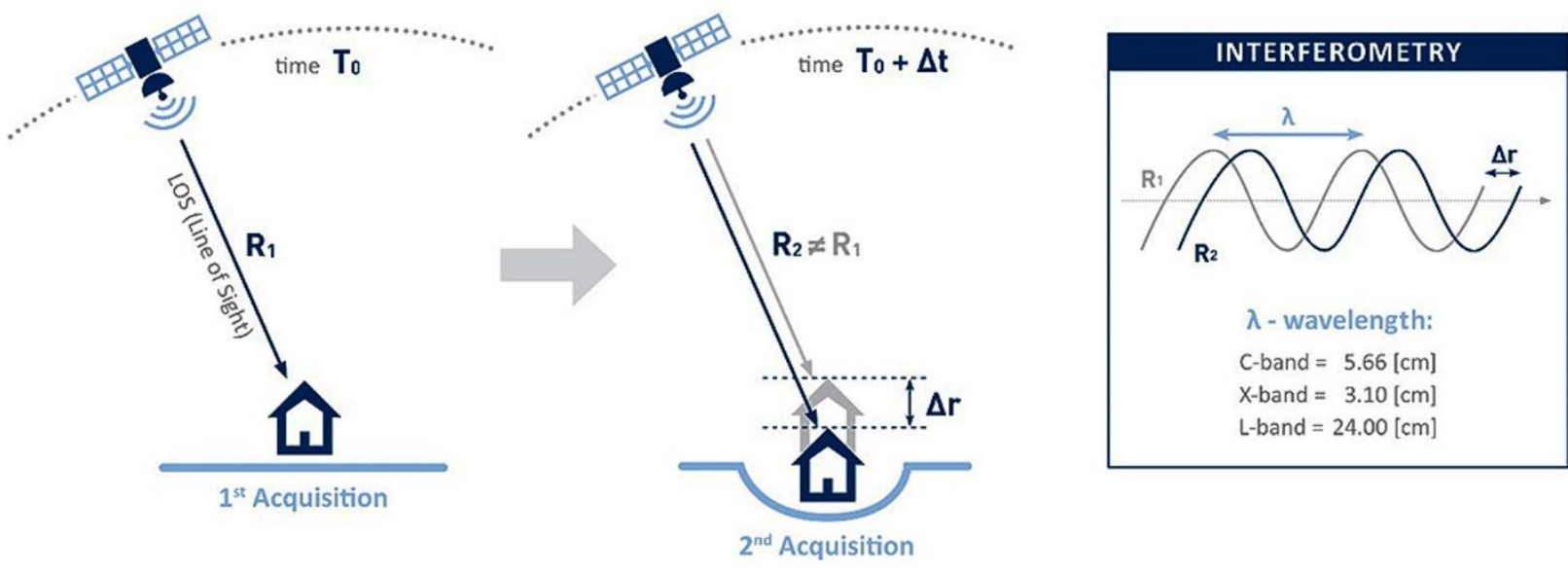

Figure 1 Illustration showing the relationship between ground displacement and signal phase shift. This is the basic principle of InSAR for measuring ground movement

In recent years, new trends have emerged with the advent of the advanced DInSAR (A-DInSAR) techniques, which are based on the data processing from multiple image acquisitions to form time series of deformation. Permanent scatterer interferometry, the first A-DInSAR technique, identifies and monitors point-wise permanent scatterers (PS), pixels that display stable amplitude, and coherent phase throughout every image of the dataset (Ferretti et al. 2000; 2001). Permanent scatterers are related to natural radar targets such as rocky outcrops, unvegetated earth surfaces, boulders, man-made structures (buildings, street lights, transmission towers, etc.), and any linear structure that can reflect a signal back to the satellite. As these types of targets are common in non-urban areas, a new technique known as SqueeSAR ${ }^{\mathrm{TM}}$ was presented by Ferretti et al. (2011) that extracts information from distributed scatterers (DS). This extends measurement point coverage to areas with limited infrastructure and which are lightly vegetated. 


\section{$3 \quad$ Mining case studies}

\subsection{Panel caving - El Teniente mine}

The El Teniente mine is located east of the city of Rancagua in the O'Higgins Region in Chile. It is the largest underground mine in the world and has an open pit operation called Rajo Sur (Figure 2). The underground operation is mined by panel caving, where rock masses are initially collapsed by means of explosives placed above the production galleries, and subsequently the caved, fractured, mineralised rock is extracted through the production galleries. Panel caving causes sequential collapses from the mined levels to the upper parts of the ore deposit, or overburden rock mass, that reach the surface and produce a large subsidence crater. This production method has been studied since the 1970s by authors such as Peck (1969), Shadbolt et al. (1972), Kvapil et al. (1989) and Flores (2005).

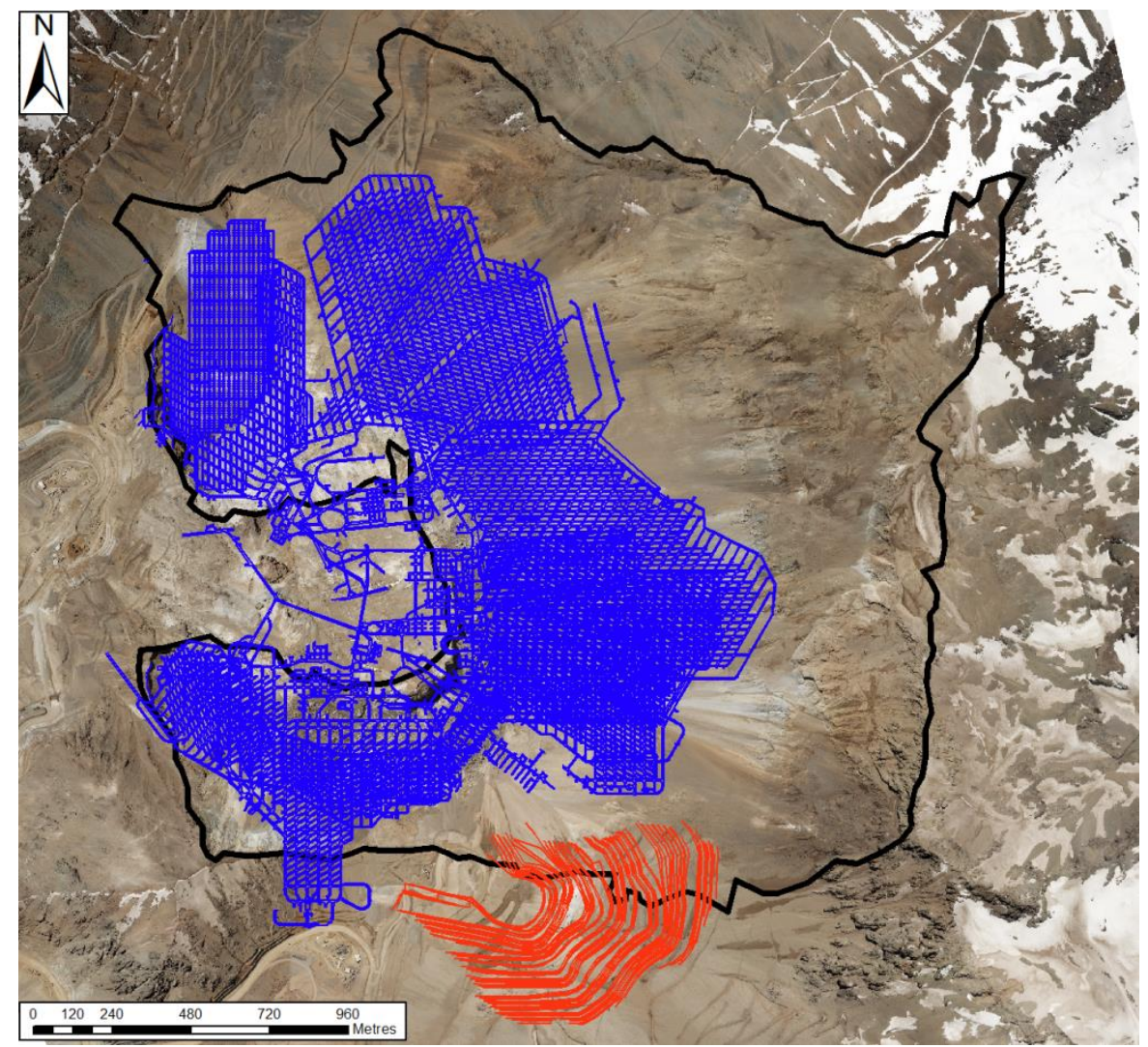

Figure 2 Map showing the location of the main areas of interest; Rajo Sur open pit (red lines); Distribution of underground mines (blue lines); Subsidence crater border (black line)

The subsidence crater of El Teniente is located in high, steep and complex topography, and the high rates of subsidence produce sink holes, large landslides and a wide variety of instabilities, all of which endanger operations in the adjacent Rajo Sur open pit. InSAR is employed at Rajo Sur to monitor pit slope stability using high-resolution COSMO-SkyMed satellite imagery. The look angle was optimised based on the topography and the orientation of the areas to be monitored and corresponded to $40^{\circ}$ off the vertical from a descending orbit.

The application of A-DInSAR identified over 200,000 measurement points. The highest rates of motion are measured at the bottom of the crater, while lower rates are observed around the borders of the pit (Figure 3). Displacement of between $2 \mathrm{~cm}$ and more than $4 \mathrm{~cm}$ are reached along the south border of the crater. Measurement points are not identified in areas where the ground surface changes too frequently (e.g. areas of active operation). 


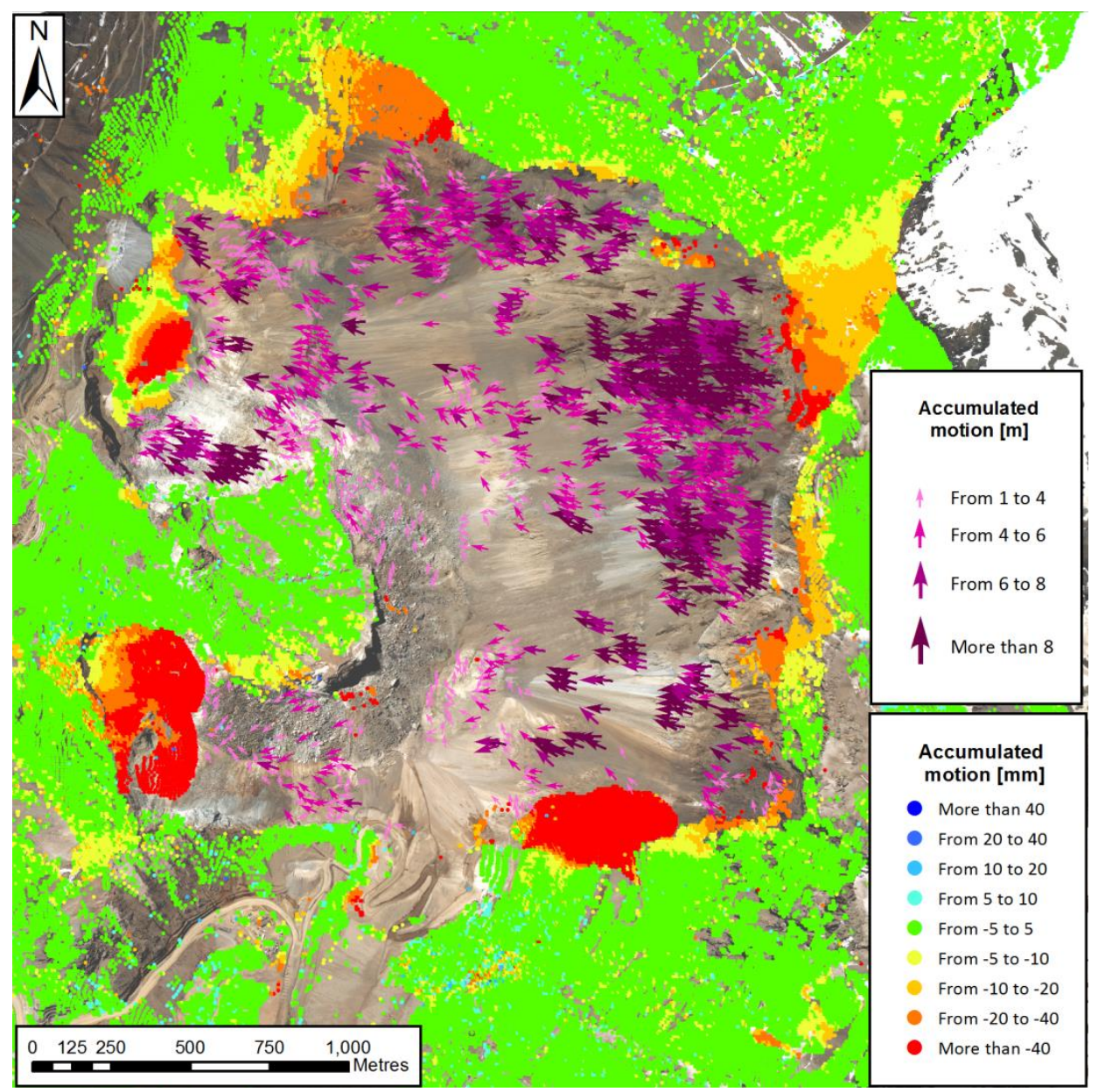

Figure 3 Ground movement measured with InSAR at the El Teniente mine

The movements observed in these areas are directly influenced by the rapid deformation within the crater and cause slow deformations, cracks, toppling and collapses. These extensive deformation areas are also related to the development of underground mining activities. In particular, the draw angles can be inferred from the extension of the areas of slow movement around the pit, using a $4 \mathrm{~cm}$ displacement as the threshold. These areas represent the limit of the area affected by underground mining at the moment of the study. The $4 \mathrm{~cm}$ threshold has been found to represent an abrupt change between two main deformation domains (i.e. millimetres/centimetres and metres) that can be used to outline and monitor the evolution of the crater border over time.

Rapid movement in the range of metres was identified at the bottom of the crater (Figure 3). For these rates of movement, the amplitude component of the radar signal is used to track pixels in two directions corresponding to the azimuth-range plane. Using this information, it is possible to produce a vector that indicates how the terrain is moving. Magnitudes less than $1 \mathrm{~m}$ are below the precision of the technique and are not included in the results.

The areas with metre-scale deformation occurring at the bottom of the crater can be directly related to the caving activities. The superficial movement quantifies the subsidence rate of the crater and produces numerous slope instabilities. Satellite InSAR monitoring identifies which sectors are the most active and the varied dynamics of the movement within the crater. Measurement point density in this area is constrained by the high rates of deformation and the rapid surface changes in this active area. The areas of strongest deformation are located on the eastern wall of the crater at the highest altitudes, reaching over $8 \mathrm{~m}$ in three months. A few other sectors around the crater show more than $4 \mathrm{~m}$ of deformation. 
The combination of slow and rapid movement monitoring provides an accurate analysis of the evolution of the crater and its border; one of the main interests for El Teniente. The thresholds used for separating slow deformation from rapid deformation allow differentiation of where the crater border begins and can be very useful in the adjustment or calibration of crater evolution models.

\subsection{Longwall mining - Metropolitan Mine}

The Metropolitan Mine is an underground coal mine located in the Southern Coalfields of New South Wales, about $40 \mathrm{~km}$ South of Sydney and in operation since 1888 (Figure 4). At present, a $3 \mathrm{~m}$ coal seam is being mined from the Bulli Seam (DeBono \& Tarrant 2011) using longwall mining. The Bulli Seam is the top seam in the Illawarra Coal Measures (Hutton 2009), and is overlain by the Narrabeen Group ( $300 \mathrm{~m}$ of sandstones, claystones and shales), a Middle Triassic quartz sandstone and the Hawkesbury Sandstone. The depth of the cover varies from 400 to $520 \mathrm{~m}$ depending on the local surface topography (DeBono \& Tarrant 2011).

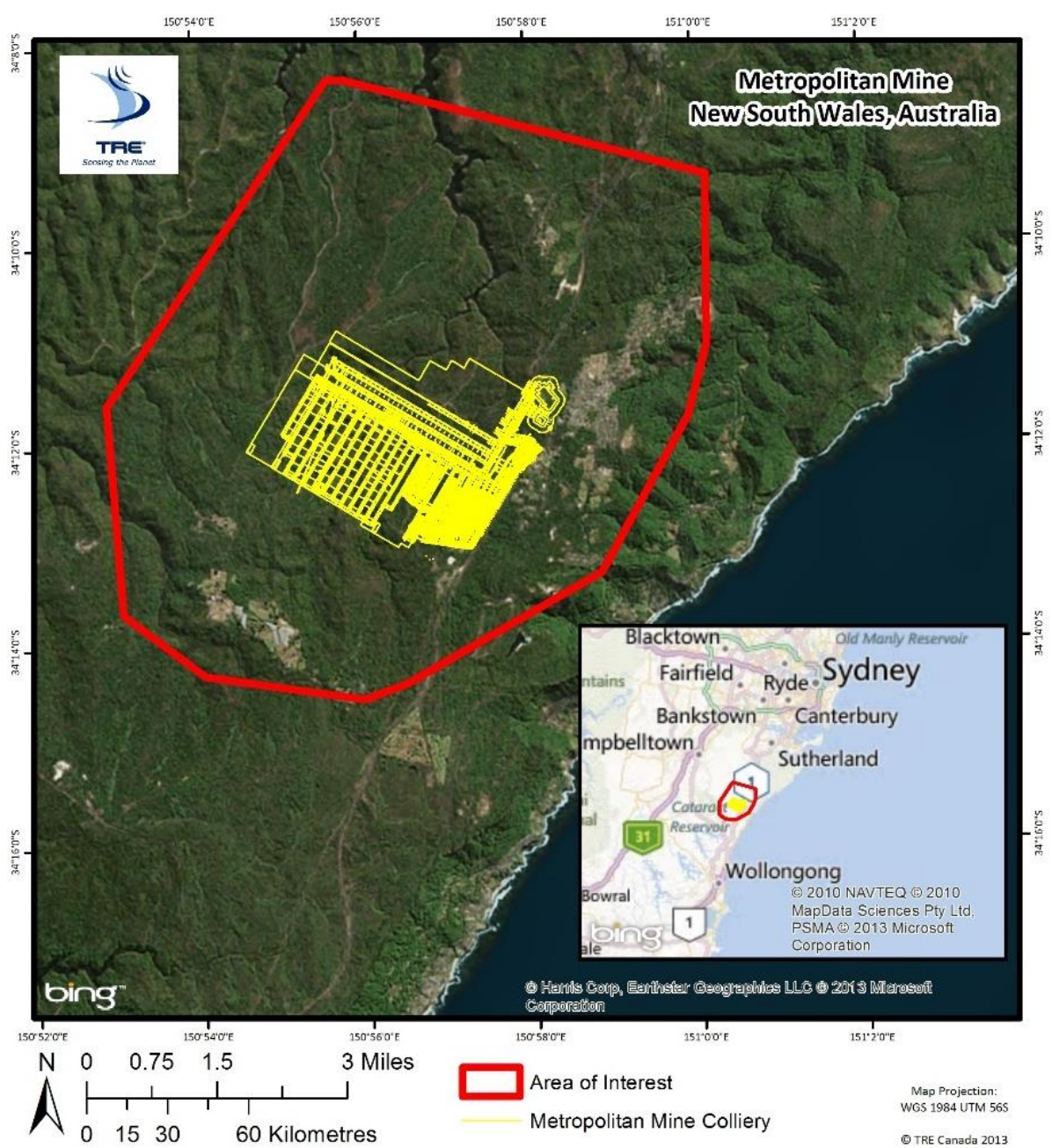

Figure 4 Location of the area of interest and layout of the longwall panels

Mining started in the area of study with Longwall 1 in 1995 and finished in April 2010 with the extraction of Longwall 18 (Figure 5). Mining progresses from the southeast towards the northwest while the extraction direction of the individual longwalls proceeds from southwest to northeast (DeBono \& Tarrant 2011; Morgan et al. 2013). Here, we focus on panels mined from June 2006 to September 2018 (Longwall 13 to Longwall 18), which corresponds to the temporal coverage of the satellite imagery. 


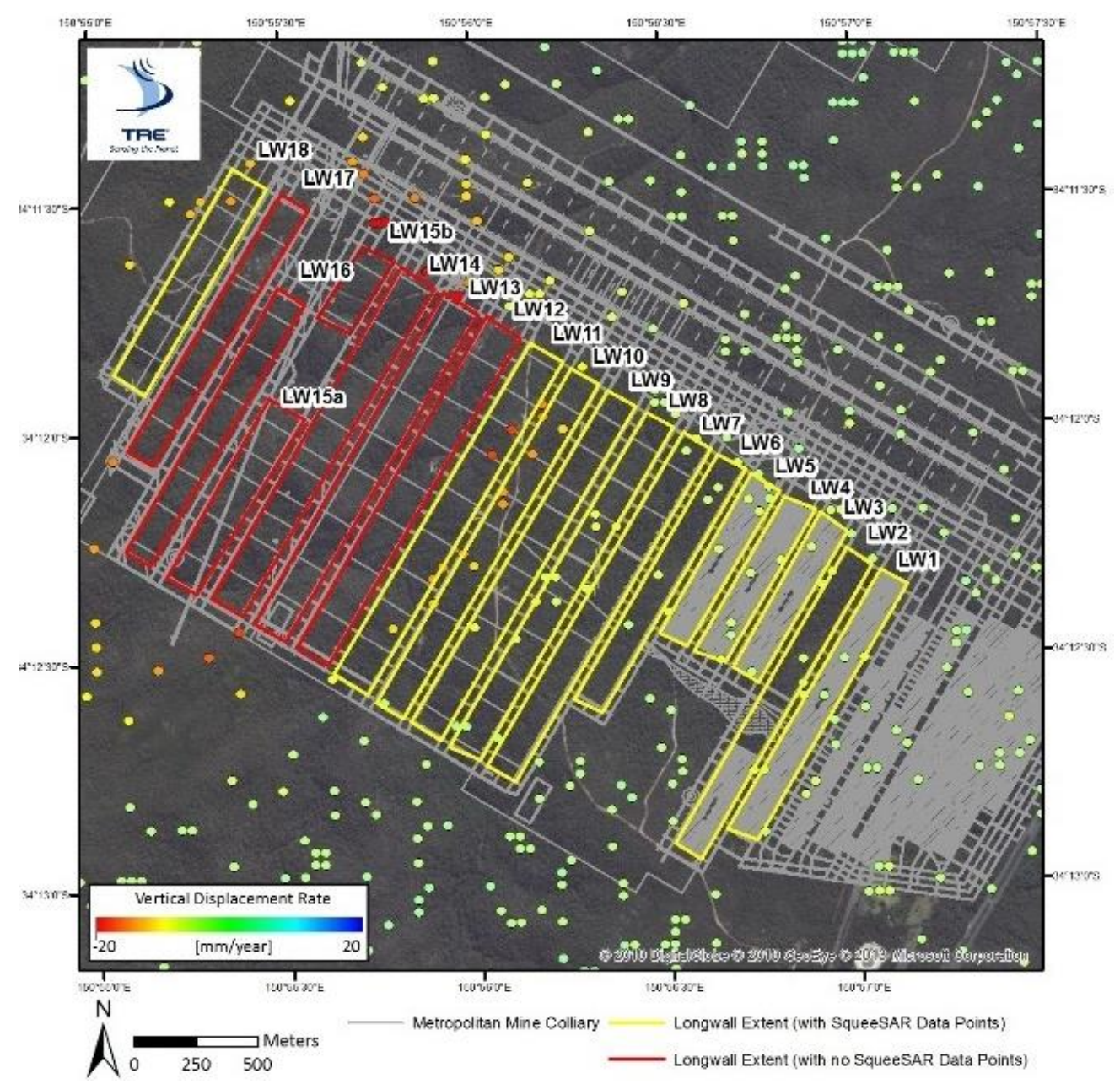

Figure 5 Longwall panel configuration with InSAR measurement points at Metropolitan Mine (from Morgan et al. 2013)

The radar imagery consists of two archives of ENVISAT radar imagery that were processed using the SqueeSAR ${ }^{\mathrm{TM}}$ algorithm (Ferretti et al. 2011). The datasets comprise 44 images acquired from an ascending orbit and 43 images acquired from a descending orbit. ENVISAT data have a nominal 35-day revisit frequency and cover the period of June 2006 to September 2010.

Longwall mining can induce large, rapid displacements in the weeks after panels are mined out, which can lead to a loss of measurement points above the longwalls. However, the focus here is to determine the extent of the subsidence area and correlate the timing of deformation with mining operations. Using this approach, the analysis highlighted a kilometre-scale subsidence bowl (Figure 6) with displacements that extend well beyond the surface area above the longwalls, and reached a cumulative value of over $150 \mathrm{~mm}$ between 2006 and 2010. The analysis of the timing of ground movement within the subsidence bowl shows very similar results for both the ascending and descending datasets, with acceleration affecting points located close to the mining front and deceleration observed once the panel has been mined. It is also interesting to note that a significant number of measurement points denotes a multi-year linear deformation trend. These points are mainly located over an older mining area, indicating that residual subsidence can last for many years after mining has terminated. 


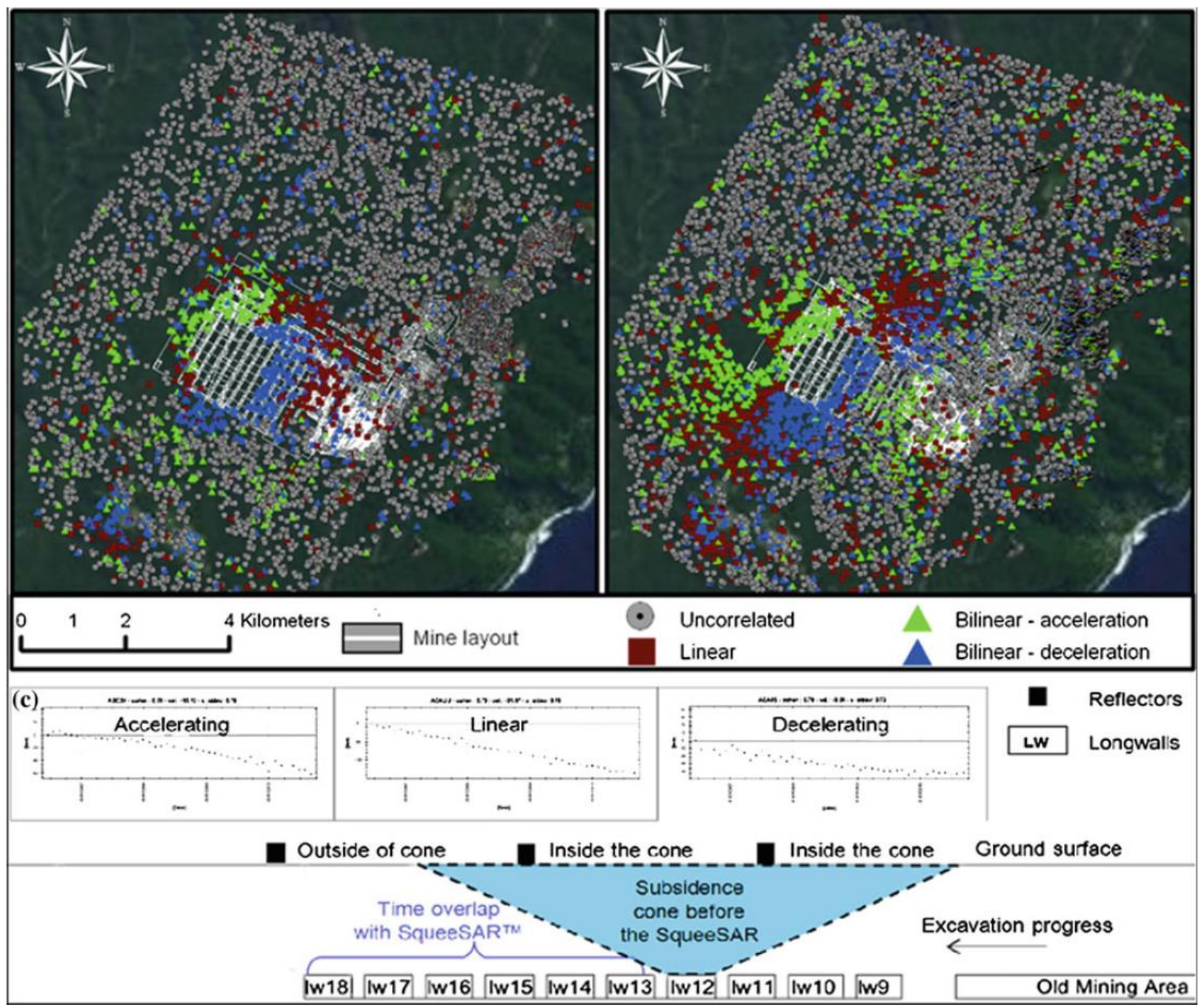

Figure 6 Measurement points over the mine workings grouped according to the behaviour of the deformation trend (from lannacone et al. 2014)

\section{Conclusion}

This paper describes the application of advanced InSAR techniques in two very different cases with different objectives. In the case of the El Teniente mine, the scope was to identify and separate the area of relatively slow subsidence from the crater formed above the area of panel caving operations, where subsidence can reach several metres within a few months and could affect the adjacent Rajo Sur open pit mine. The evolution of the InSAR technique now allows movements, both slow and rapid, to be tracked for a complete characterisation of ground deformation affecting mining areas.

In the longwall mining example, an analysis of historical satellite archives revealed the relationship between mining operations and displacement. During active operations, the areas near recently mined panels tend to accelerate, while movement decelerates once the longwall has been extracted. It is observed that slow deformation can continue for many years after an area has been mined.

\section{Acknowledgement}

The authors thank the Codelco El Teniente Division in Rancagua, and the University of New South Wales for their support. 


\section{References}

Bamler, R \& Hartl, P 1998, 'Synthetic aperture radar interferometry', Inverse Problems, vol. 14, pp. R1-R54.

Carnec, C \& Delacourt, C 2000, 'Three years of mining subsidence monitored by SAR interferometry, near Gardanne, France', Journal of Applied Geophysics, vol. 43, pp. 43-54.

Colesanti, C, Mouelic, SL, Bennani, M, Raucoules, D, Carnec, C \& Ferretti, A 2005, 'Detection of mining related ground instabilities using the Permanent Scatterers technique: a case study in the east of France', International Journal of Remote Sensing, vol. 26, no. 1, pp. 201-207.

DeBono, P \& Tarrant, G 2011, 'An analysis of long term subsidence at Metropolitan colliery', Proceedings of the Eighth Triennial Conference on Management of Subsidence, Mine Subsidence Technological Society, Pokolbin, pp. 81-88.

Espinosa, AE, Mora, O \& Sanchez, F 2014, 'Application of InSAR technique for monitoring and control of surface subsidence generated by underground mining', in R Castro (ed), Proceedings of the 3rd International Symposium on Block and Sublevel Caving, Universidad de Chile, Santiago, pp. 603-610.

Ferretti, A, Prati, C \& Rocca, F 2000, 'Nonlinear subsidence rate estimation using permanent scatterers in differential SAR interferometry', IEEE Transactions on Geoscience and Remote Sensing, vol. 38, no. 5, pp. 2202-2212.

Ferretti, A, Prati, C \& Rocca, F 2001, 'Permanent scatterers in SAR interferometry', IEEE Transactions on Geoscience and Remote Sensing, vol. 39, no. 1, pp. 8-20.

Ferretti, A, Fumagalli, A, Novali, F, Prati, C, Rocca, F \& Rucci, A 2011, 'A new algorithm for processing interferometric data-stacks: SqueeSAR', IEEE Transactions on Geoscience and Remote Sensing, vol. 49, no. 9, pp. 3460-3470.

Flores, GE 2005, Rock Mass Response to the Transition From Open Pit to Underground Cave Mine, PhD thesis, The University of Queensland, Brisbane.

Gabriel, AK, Goldstein, RM \& Zebker, HA 1989, 'Mapping small elevation changes over large areas: differential radar interferometry', Journal of Geophysical Research, vol. 94, pp. 9183-9191.

Herrera, G, Tomás, R, Lopez-Sanchez, JM, Delgado, J, Mallorqui, JJ, Duque, S \& Mulas, J 2007, 'Advanced DInSAR analysis on mining areas: La Union case study (Murcia, SE Spain)', Engineering Geology, vol. 90, pp. 148-159.

Herrera, G, Tomas, R, Vicente, F, Lopez-Sanches, JM, Mallorquí, JJ \& Mulas, J 2010, 'Mapping ground movements in open pit mining areas using differential SAR interferometry', International Journal of Rock Mechanics \& Mining Sciences, vol. 47, pp. 1114-1125.

Hutton, AC 2009, 'Geological setting of Australasian coal deposits', in R Kininmonth \& E Baafi (eds), Australasian Coal Mining Practice, The Australasian Institute of Mining and Metallurgy, Melbourne, vol. 3053, pp. 15-31.

lannacone, JP, Corsini, A, Berti, M, Morgan, J \& Falorni, G 2014, 'Characterization of longwall mining induced subsidence by means of automated analysis of InSAR time-series', Engineering Geology for Society and Territory, vol. 5, pp. 973-977.

Jung, HC, Kim, SW, Jung, HS, Min, KD \& Won, JS 2007, 'Satellite observation of coal mining subsidence by persistent scatterer analysis', Engineering Geology, vol. 92, pp. 1-13.

Kvapil, R, Ceccarelli, B \& Lonergan, J 1989, Quantitative Analysis of Subsidence at El Teniente mine, technical report, El Teniente Division, CODELCO-Chile.

Massonnet, D \& Feigl, KL 1998, 'Radar interferometry and its application to changes in the Earth's surface', Reviews of Geophysics, vol. 36, no. 4, pp. 441-500.

Morgan, J, Raval, S, Macdonald, B, Falorni, G \& lannacone, JP 2013, 'Application of advanced InSAR techniques to detect vertical and horizontal displacements', in PM Dight (ed.), Proceedings of the 2013 International Symposium on Slope Stability in Open Pit Mining and Civil Engineering, Australian Centre for Geomechanics, Perth, pp. 829-840.

Paradella, WR, Ferretti, A, Mura, JC, Colombo, D, Gama, F, Tamburini, A, Santos, AR, Novali, F, Galo, M, Camargo, PO, Silva, AQ, Silva, GG, Silva, A \& Gomes, LL 2015, 'Mapping surface deformation in open pit iron mines of Carajas Province (Amazon Region) using an integrated SAR analysis', Engineering Geology, vol. 193, pp. 61-78.

Peck, RB 1969, 'Deep excavation and tunnelling in soft ground - state of the art', Proceedings of the 7th International Conference on Soil Mechanics and Foundations, Sociedad Mexicana de Mecánica de Suelos, pp. 225-290.

Raucoles, D, Maisons, C, Carnec, C, Mouelic, SL, King, C \& Hosford, S 2003, 'Monitoring of slow ground deformation by ERS radar interferometry on the Vauvert salt mine (France): comparisons with ground-based measurement', Remote Sensing of Environment, vol. 88, pp. 468-478.

Rosen, P, Hensley, S, Joughin, I, Li, F, Madsen, SN, Rodriguez, E \& Goldstein, R 2000, 'Synthetic aperture radar interferometry', Proceedings of the IEEE, vol. 88, no. 3, pp. 333-382.

Sánchez, F, Conde, A \& Salvá, B 2017, 'Use of SAR radar satellite data to measure ground deformation in underground and open pit mine sites, El Teniente case study, Chile', in PM Dight (ed.), Proceedings of the First Asia Pacific Slope Stability in Mining Conference, Australian Centre for Geomechanics, Perth, pp. 379-386.

Shadbolt, CH 1972, 'Subsidence engineering', University of Nottingham Mining Department Magazine, vol. 24, pp. 80-89. 